\title{
POSSIBILITIES OF USING ARTIFICIAL INTELLIGENCE IN POST-PANDEMIC GEORGIA
}

\author{
GIULI GIGUASHVILI \\ $\mathrm{PhD}$ in Economics, Professor \\ Gori State Teaching University, Georgia \\ giuligiguashvili@gmail.com
}

\section{TAMAR MAKASARASHVILI}

PhD in Economics, Professor

Gori State Teaching University, Georgia

tmakasarashvili@gmail.com

Abstract. The COVID-19 pandemic has caused an economic crisis in almost every country in the world and has exacerbated economic, social, cultural, legal, educational, and other problems. Artificial intelligence, as the technology of the future, offers new ways to solve the problems of the post-pandemic period, to make technological decisions, to develop business processes using modern innovative advances, to improve management processes, to improve medical services opportunity etc.

Artificial intelligence is a field of special interest for researchers, one of the promising technologies of modern digital culture, which seeks not only to understand the nature of intelligence but also to create artificial systems with intelligent behavior.

The potential of artificial intelligence can be harnessed in healthcare, agriculture, finance, energy, communications, economics, cybersecurity, and many more. However, artificial intelligence is associated with many risks, such as its use for criminal purposes, loss of jobs, or potential replacement.

The main goal of the research is to determine the possibilities of introducing artificial intelligence systems in Georgia in the post-pandemic period, to select innovative approaches to increase economic efficiency, and to find ways to solve the postpandemic socio-economic problem.

In the scientific paper, to determine the possibility of using artificial intelligence in the post-pandemic period and indepth analysis of the current situation, both Georgian and foreign scientific literature, studies, and statistical data were studied. Using quantitative-statistical research methods, some conclusions and recommendations were developed based on the sharing of existing practices related to the use the artificial intelligence.

Artificial intelligence plays a special role in the process of sustainable development of the post-pandemic economy and maximization of economic prosperity.

\section{KEYWORDS: ARTIFICIAL INTELLIGENCE, POST-PANDEMIC ECONOMICS.}

For citation: Giguashvili, G., Makasarashvili, T. (2021). Possibilities of Using Artificial Intelligence in Post-Pandemic Georgia. Globalization and Business. 12, 83-87. https://doi.org/10.35945/gb.2021.12.011

\section{INTRODUCTION}

The global crisis caused by COVID-19 has significantly affectedalmostallareasofeconomicactivity. Theconsequences of the so-called "lockdown" against the pandemic were especially severe for developing, small economy countries, including Georgia. Although the management of restrictions in our country is mainly carried out taking into account the analysis of the situation, international recommendations, the expected risks, the results are still unfavorable. The declining pace of economic growth, deteriorating living standards, the crisis in the health care system, deplorable indicators of the quality of education, the devalued national currency, and rising unemployment - these are just a few of the problems that post-pandemic Georgia is facing.

Along with anti-crisis measures already implemented and planned by the government (social support for citizens, assistance to entrepreneurs, economic promotion and attracting international financial flows, etc.), it is important to implement digital technologies, in particular artificial intelligence systems, In recovery and development (Report, 2020). 


\section{Relevance of the Research Topic}

Artificial intelligence has the potential to enhance traditional approaches to managing socio-economic processes. The technologies of the future will enable people living in developing countries to overcome poverty and enjoy the high standards of living that the developed countries of the world have. The use of artificial intelligence increases productivity, reduces costs, gives us new knowledge, new opportunities for making technological decisions. (Chen, 2016)

\section{Aim of Research}

The main goal of the research is to identify the possibilities of introducing artificial intelligence systems in Georgia in the post-pandemic period, to select innovative approaches, to increase economic efficiency, and to find ways to solve the post-pandemic socio-economic problem.

Artificial intelligence is a field of special interest for researchers. According to numerous international studies, by 2030 , artificial intelligence could provide additional economic effects of 10 to 15 trillion dollars, which creates huge prospects for economic growth and high productivity.

\section{Research Methodology}

In the post-pandemic period, to determine the possibility of using artificial intelligence and in-depth analysis of the current situation, both Georgian and foreign scientific literature, studies and statistical data were studied. Using quantitative-statistical research methods, some conclusions and recommendations were developed based on the sharing of existing practices related to the use of artificial intelligence.

\section{Discussion and Results}

An important source for rapidly growing artificial intelligence (Al) is the billions of gigabytes of data generated daily through various platforms, which can accelerate the process of globalization and expand economic boundaries between many countries and companies around the world. The potential of artificial intelligence can be harnessed in healthcare, agriculture, finance, energy, communications, economics, cybersecurity, and many more (Giguashvili, 2019). However, artificial intelligence is associated with many risks, such as its criminal use, potential job replacement, or loss. Because of this, Microsoft co-founder Billy Gates even came up with an initiative to tax robots. According to him, the funds received from the taxation of robots should be distributed to the poor, unemployed, and disabled children, although this idea has many opponents. In 2017, the European Parliament unequivocally rejected the idea of imposing a tax on robot owners - to fund support for the training of workers fired because of robots. The heated debate over the introduction of digital economy taxes continues today at both EU and international levels (European Parliament, 2019).

Involvement of the educational system in the process of studying and using artificial intelligence is important. Many universities around the world offer artificial intelligence education programs, including the University of Manchester, the Royal College of London, the Universities of Georgia, Edinburgh, Amsterdam, the Pierre and Marie Curie University in Paris, the University of Sofia, and many more. Some steps have been taken in our country as well - in 2003 the Department of Artificial Intelligence was established at the Georgian Technical University (https://gtu.ge/), at the Georgian University of Business and Technology (https://btu.edu.ge) there is a doctoral program "Digital Governance and Artificial Intelligence"; Large-scale research is underway to develop a national strategy for artificial intelligence, which will facilitate the formation of research infrastructure, the preparation of a legal framework, the adaptation of the education system to new systems.

The first artificial intelligence business association Al Georgia was established in Georgia in 2019, to promote artificial intelligence as a field in the country and raise awareness in this regard, as well as to conduct research in this field and introduce intellectual technologies in the country. Georgia Mind - The main mission of the Artificial Intelligence Business Association is to popularize and promote the introduction of artificial intelligence in the private sector; Ensuring dialogue between business companies, the executive, and the legislature (http:// www.aigeorgia.ge). According to Al Georgia, Georgia is a small emerging economy and is developing artificial intelligence or other digital technologies quite slowly. There is virtually no penetration of $\mathrm{Al}$ at the state or private level. However, we have the potential to develop artificial intelligence.

Special attention was paid to the introduction of artificial intelligence in Georgia on October 22-23, 2019, at the third forum of the Silk Road in Tbilisi. Prospects and challenges for the development of artificial intelligence in the new Silk Road countries were discussed in a panel discussion entitled "Innovation-driven growth - the Silk Road with Artificial Intelligence." According to Irakli Beridze, the Head of the UN Center for Artificial Intelligence and Robotics, the use of artificial intelligence in the economy and public life is extremely important. "Georgia is actively involved in these processes: it is planned to create a national strategy; we already have interesting startups and state-government initiatives, which will present quite good results for our country." According to Nikoloz Alavidze, the Deputy Minister of Economy and Sustainable Development of Georgia, further development of artificial intelligence will help our region and countries become more productive. "We are a small country, but we are partners for the global world. We think locally, but we act globally. This is our chance ... Artificial intelligence will be the next step in our daily life," said Nikoloz Alavidze (Alavidze, 2019).

The analytical organization "GeoCase" has dedicated many events to the analysis of both the opportunities and challenges of artificial intelligence. According to "Geocase" researchers, artificial intelligence can not only develop 
digital governance, digital policy, but also transform systems in certain fields, including health, education, agriculture, and justice (https://www.geocase.ge/). The use of artificial intelligence is especially important in the field of national security and defense, in particular, in terms of defense and borders (Bodzashvili, 2021). In addition, attention should be paid to ethical norms. Numerous papers by academics, public and private, and companies on the ethical use of artificial intelligence have been published. In The Future Computed, Microsoft outlined the basic principles of artificial intelligence ethics: equity, reliability, privacy and security, inclusiveness, transparency, and accountability. (https://softlinegeorgia. ge/) Technologies affect not only competitiveness, business success, and its viability, but also the world and society around it. The Institute for Electrical and Electronics Engineers (IEEE), the world's largest technology organization, has launched a global initiative on the ethical norms of autonomous and intelligent systems, which aims to protect human rights and well-being through the use of new technologies, including artificial intelligence. (Goderdzishvili, 2021).

For the introduction of artificial intelligence in the country, there must be a practice of large-scale use of highly developed ICT infrastructure and digital governance, compatible databases. The British international consulting group Oxford Insight has been processing data since 2017 and publishing the artificial intelligence readiness index of 172 countries, which consists of three main components:

- Governance component: goals, governance framework, and ethical norms, digital skills and adaptability;

- Technology sector: human capital, innovation opportunities, the scale of the technology sector;

- Data and infrastructure: infrastructure, data availability, data quality.

According to the Oxford Insight Al Readiness Index 2020, Al leads the country in 172 countries in terms of state readiness: the United States, the United Kingdom, Finland, Germany, France, Singapore, South Korea, Denmark, the Netherlands, and Norway. Georgia ranks 72 nd in the global context in this index, and 5th out of 16 countries in the region (South and Central Asia) (43.39) and lags behind countries in the region such as Turkey (46.01), Azerbaijan (46.44) Kazakhstan (46.55), India (55.58). The 2020 Index emphasizes that despite a supportive business environment, Georgia lacks an Al strategy, lacks a systematic approach to ICT ecosystem development, including private sector investment policies, and sector development programs, with the addition of underdeveloped infrastructure. (Goderdzishvili, 2021)

Of some interest is the Bloomberg Innovation Index (https://www.bloomberg.com/europe), which has been published since 2013 and mainly assesses countries' innovation potential (including research and development costs, production capacity, and concentration of high-tech public companies). The 2021 ranking reflects a world where the fight against the Covid-19 pandemic has accelerated the development of digital infrastructure, which in turn will help revitalize the economy and speed up the vaccination process. At the top of the top, ten most innovative countries in 2021 is South Korea, which replaced last year's leader - Germany. It is now in 4th place. 2nd and 3rd places are shared by Singapore and Switzerland, followed by Sweden, Denmark, Israel, Finland, the Netherlands, and Austria. The U.S. left the top ten this year and moved into 11th place. (Jamrisko, 2021).

Georgia is not among the top 60 countries, but the index also includes the indicators of our country. According to the latest research from 2021 , only $0.30 \%$ ( $\$ 130$ million) of our country's GDP is spent on research and development, which is a prerequisite for digital transformation in the postCold era. Ten years ago, that figure was $0.18 \%$ (\$32 million). The growth is visible, but we are still far behind the pace at which modern technologies are advancing. For example, Belarus spends twice as much as us, Bulgaria 2.5 times more, three times more than Hungary and Estonia. (https://www. youtube.com/watch?v=KIhH4K2st7Q)

The United Nations 2020 e-Government Survey (United Nations, 2020), which discusses new trends in digital transformation, has a special place in the use of new technologies, namely artificial intelligence and blockchain, especially in the development of the concept of smart cities. According to the 2020 estimate, Georgia's e-governance rate is 0.72 , which ranks Georgia 65th among 193 countries (IDFI, 2020).

The issue of the introduction of artificial intelligence and the use of its capabilities has become particularly acute in the pandemic. COVID-19 has posed numerous challenges to the artificial intelligence (AI) community. These challenges include: Can Al help predict the spread of infection, diagnosis, how can it be used in treatment and vaccine research, and how can it be used for social control? (Naudé, 2020). Numerous studies are conducted around the world to answer these questions. Various initiatives are being taken to collect and share data, to create new Al models. These include the World Health Organization (WHO) Global Coronavirus Database Survey, as well as the GISAID Initiative (formerly the Global Influenza Data Exchange Initiative) for open access to data. Noteworthy is the joint initiative of the Allen Institute of Artificial Intelligence, Microsoft, Facebook, and others to create the COVID-19 Open Research Database (CORD-19), which includes nearly 44,000 open access scientific articles for intelligent data analysis. Elsevier has published both early-stage and peer-reviewed research and up to 20,000 articles on the new coronavirus in the COVID-19 Information Center (Naudé, 2020).

According to American researchers (Christina M. Williams, Rahul Chaturvedi, Richard D. Urman, Ruth S. Waterman \& Rodney A. Gabriel), one of the main advantages of artificial intelligence in a pandemic environment such as COVID-19 is the potential for faster diagnosis of the disease. In addition, it can assess health system resources and predict epidemics. Researchers believe that the use of artificial intelligence will reduce the time it takes for a patient to become infected and treat them effectively, which in turn will reduce morbidity and mortality. For example, the Al-based HealthMap system at Boston Children's Hospital (USA) was the first to notify the world of the coronavirus on December 30, 2019, just days before the announcement by the World Health Organization. 
However, it is necessary to take into account the issues of bias and security (Williams, 2021).

The fact that artificial intelligence can predict the spread of disease is confirmed by the example of an artificial intelligence-based research system at the Weitzman Institute of Science in Israel. The system uses a key questionnaire focused on key health issues and isolation methods. It then compares these responses to an algorithm that allows for the early detection of potential hotspots and the prediction of virus outbreaks. An example of the use of artificial intelligence in a pandemic is the Canadian multilingual virtual assistant Stallion.ai, which answers questions about the virus, including sorting out symptoms and providing information from trusted and verified sources such as the World Health Organization and the Centers for Disease Control and Prevention.

Artificial intelligence is becoming increasingly important in the fight against disinformation. Technology giants like Google and Facebook are using artificial intelligence capabilities to determine the validity of the information. It should be noted that the lack of human control at an early stage will increase the risk of error, although in the future it may lead to the creation of new, more sophisticated tools of artificial intelligence. Artificial intelligence can identify patients. A computer vision algorithm has been developed to scan people's temperatures in public places in China. Everyone who has a fever is identified and a person who does not use a pill is identified. Another artificial intelligence algorithm helps doctors accurately distinguish between patients with coronavirus and typical pneumonia. With the help of robots, items, furniture, and flats can be disinfected completely automatically, without human intervention. In Washington State, robots were used for remote treatment and communication to prevent the disease from spreading from patients to doctors (Popomaronis, 2020).

As mentioned above, cowardice and massive constraints have affected all sectors of the economy. There is a global economic recession: rising unemployment, small and medium-sized businesses Bankruptcy, disruption of tourism and aviation sector, catastrophic oil disaster Lee drop, record drop in the stock market, etc. Most economics researchers believe that pandemic shock management is different from economics. It is dependent on the timing of the spread of the virus, the outbreaks, and the aggressiveness. At the same time, during the pandemic, the importance and scope of those areas of economics are also directly related to human life and health. Therefore, in the post-pandemic period, special attention should be paid to the innovative development of the economy; Medicine, biotechnology and healthcare systems, agriculture, digital economy on the Development of Art, and Artificial Intelligence. He wanted to introduce online learning, online trading, and distance business, which, In addition to human safety, it will cause significant resource savings and time Savings (Abesadze, 2020).

We think that in the post-pandemic period, artificial intelligence can be actively used in all areas of service and production. Self-driving cars that move without the driver's effort are indeed only a distant prospect for Georgia, but partly the new generation of cars already use artificial intelligence as a voice assistant or a semi-self-driving function. Production
- this is the field that is most dependent on artificial intelligence and automated services. Robots are much more productive than humans. In the long run, artificial intelligence can be used on a large scale in the field of shipping (Chymis, 2020). According to data collected by Learn Bonds (https:// learnbonds.com/), the largest investment news platform in the world, the artificial intelligence market in the world, valued at 22.6 billion USD by 2020, will increase to 126 billion USD by 2025 . The leader in this direction is North America, followed by the Asia-Pacific region (Jastra llic, 2020).

Digital workers and hybrid workforce, software robots, and $\mathrm{Al}$ automation have already been established massive roles in manufacturing, retail, banking, and insurance. They also play a big role in investment and lending platforms where sophisticated computer algorithms make business decisions faster and more error-free than humans.

The scientific literature and EU policy papers do not provide a unified approach to the impact of artificial intelligence on the labor market; researchers and politicians, on the one hand, welcome the development of new technologies and, on the other hand, discuss the risks of job loss by the workforce. According to the KMPG 2019 global survey, almost $75 \%$ of respondents said that the introduction of intelligent technologies would have a significant impact on $50 \%$ of their workforce (Jastra Ilic, 2020).

Data differ on the extent of the impact of artificial intelligence on labor relations in different countries, for example, it is $47 \%$ in the US, $35 \%$ in the UK, $36 \%$ in Finland, $69 \%$ in India, $77 \%$ in China, and so on (Joamets, 2020).

Although automation and the use of Al are associated with job losses, to save many lives and reduce the harmful effects of the virus due to the widespread pandemic in the world, it is necessary to accelerate the digitization of the economy, to use the capabilities of artificial intelligence more actively. Individual researchers predict that increased integration between humans and digital workers is expected shortly, creating a new hybrid workforce that is likely to reduce costs, improve efficiency, and create better products and services for consumers.

\section{CONCLUSIONS}

Thus, a pandemic can be viewed as a stimulating process that can accelerate society's progress in developing appropriate mechanisms for managing artificial intelligence. Consider that the introduction and development of artificial intelligence technologies in Georgia will create new opportunities for the development of a post-pandemic economy. It should also be noted that the development of artificial intelligence technologies reduces the use of human capital, which in turn increases the risks of rising unemployment. Thus, it is extremely important to evaluate the full potential of artificial intelligence technology, maximize benefits, and minimize risks.

When determining the economic policy of a country, it is important to remember that artificial intelligence does not mean only the emergence of high-tech startups in the 
market. The main thing is to introduce artificial intelligence technologies in all sectors, which is possible through the joint efforts of the state, business and education sectors. Without technology, economic growth will be impossible. Barriers that exist in this area primarily include problems in the education system, the lack of digital entrepreneurial culture, and strict pandemic regulations that can be addressed through the active involvement of the state.

\section{REFERENCES:}

Abesadze, R. (2020). Globalization and the Economic Problems of the Pandemic, URL: http://conferenceconomics.tsu. ge/?leng=ge\&cat=pers, (In Georgian).

Alavidze, N. (2019). Innovation Driven Growth - Artificial Intelligence (Al) for Silk Road, URL: http://www.economy.ge/index. php?page=news \&nw=1292

Artificial Intelligence Business Association- Al Georgia, URL: http://www.aigeorgia.ge

Bloomberg, URL: https://www.bloomberg.com/europe

Bodzashvili, L. (2021). Artificial Intelligence and National Security, Georgian Foundation for Strategic and International Studies. URL: https://www.gfsis.org/files/library/opinion-papers/154-expert-opinion-geo.pdf

Business and Technology University (BTU), URL: https://drive.google.com/file/d/1_eOlblpkrFSujClhDxxmddA0GOlaCbMN/view

Chen, N., Christensen, L., Gallagher, K., Mate, R., \& Rafert, G. (2016). Global Economic Impacts Associated with Artificial Intelligence; Economic Impact Study, February 2016. URL: https://www.analysisgroup.com/uploadedfiles/content/ insights/publishing/ag_full_report_economic_impact_of_ai.pdf

Williams, C. M., Chaturvedi, R. R., Urman, R. D., Waterman R. S., \& Gabriel, R. A. (2021). Artificial Intelligence and a Pandemic: an Analysis of the Potential Uses and Drawbacks. Journal of Medical Systems, 45(26). URL: https://link.springer.com/ article/10.1007/s10916-021-01705-y

Chymis, A. (2020). Artificial Intelligence in the post-COVID-19 era, Journal Homo Virtualis 3 (2): 55-67, DOI: https://doi. org/10.12681/homvir.25449, URL: https://ejournals.epublishing.ekt.gr/index.php/homvir/article/view/25449/20968

European Parliament, (2019). Economic impacts of artificial intelligence (AI), URL: http://www.europarl.europa.eu/RegData/ etudes/BRIE/2019/637967/EPRS_BRI(2019)637967_EN.pdf

GeoCase - Annual Report. January 2021. URL: https://www.geocase.ge/ka, (In Georgian).

Georgia in the UN E-Government Survey - Review of 2020 Results, The Institute for Development of Freedom of Information (IDFI), URL: https://idfi.ge/en/e-governance-e-participation-georgia-index-2020

Georgian Technical University, Department of Artificial Intelligence, URL: https://gtu.ge/Ims/Faculty/xelovnuri_inteleqti.php

Giguashvili, G., Makasarashvili, T., Khorguashvili, T., (2019). „Artificial Intelligence Systems Development Opportunities in Georgia", International Journal of Innovative Science and Research Technology (IJISRT), www.ijisrt.com, 4(12) -

December. URL: https://www.ijisrt.com/assets/upload/files/IJISRT19DEC554_(1).pdf

Goderdzishvili, N. (2021). Artificial Intelligence: Meaning, International Standards, Ethical Norms, Recommendations and Conclusions. The Institute for Development of Freedom of Information (IDFI), URL: https://idfi.ge/public/upload/ Article/1111Artificial-Intelligence-ENG_Web\%20Version.pdf

Jamrisko, M., Lu, W., \& Tanzi, A. (2021). South Korea Leads World in Innovation as U.S. Exits Top Ten. URL: https://www. bloomberg.com/news/articles/2021-02-03/south-korea-leads-world-in-innovation-u-s-drops-out-of-top-10

Jastra Ilic, (2020). Global Al Software Market to Grow Five Times and Reach \$126bn Value by 2025. URL: https://learnbonds. com/news/global-ai-software-market-to-grow-five-times-and-reach-126bn-value-by-2025/

Joamets, K., \& Chochia, A., (2020). Artificial Intelligence and Its Impact on Labor Relations, TSU, Journal of Law, 1, URL: https:// tsu.ge/assets/media/files/8/Publications/LAW-jurnal2020-1.pdf, (In Georgian).

Naudé, W. (2020). Artificial intelligence vs COVID-19: limitations, constraints and pitfalls. Al Soc.:1-5, 2020. https://doi. org/10.1007/s00146-020-00978-0. URL: https://link.springer.com/article/10.1007\%2Fs00146-020-00978-0

Popomaronis, T. (2020). 4 Ways Artificial Intelligence Makes the Universe Safer, URL: https://www.entrepreneur.com/ article/349362, (In Georgian).

Report about the measures taken by the Georgian Government against the COVID-19, URL: http://gov.ge/ files/76338_76338_444796_COVID-19angarishi...pdf, (In Georgian).

United Nations E-Government Survey 2020, Digital Government in the Decade of Action for Sustainable Development With addendum on COVID-19 Response, URL: https://publicadministration.un.org/egovkb/en-us/Reports/UN-E-GovernmentSurvey-2020

What values should we introduce to artificial intelligence? 12.01.2021. URL: https://softlinegeorgia.ge/about/blog/-values-inartificial-intelligence- 